\title{
O papel do espaço nas memórias da infância
}

\section{The relation of the child with the space in the memories of childhood}

Ailton José Morelli ${ }^{1}$

\begin{abstract}
Resumo
O presente texto é parte de uma pesquisa mais ampla que objetivou a análise das memórias sobre infâncias durante a urbanização da cidade de Maringá, entre 1970 e 1990. Para analisar como esse processo foi vivido pelas crianças da época, o uso de fontes orais demonstrou ser o mais indicado. O trabalho com as fontes orais, além de analisar como o processo complexo de urbanização da cidade ficou registrado na memória dos depoentes, ainda permitiu o aprofundamento na questão da formação da memória da infância nos adultos. O presente recorte está centrado na relação da criança com o espaço na formação de sua visão de mundo e a importância desse processo na formação da memória dessa fase.
\end{abstract}

Palavras-chave: Infância; Memória; Espaço.

\section{Introdução}

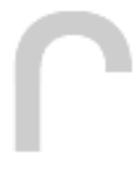

\begin{abstract}
This article is part of a wider research that studied memories of childhood in the context of Maringa's urbanization between 1970 and 1990. Analyzing this process, through the eyes of children growing up during this era, the use of oral sources demonstrated being the most indicated. The analysis of these oral sources, besides lending insight into the complexities of Maringá's urbanization, also shows just how profoundly childhood recollections remain in memory and shape adult lives. The focus is the relation that the child maintains with the space in the formation of her worldview and the importance of this process to the formation of her memory of this phase.
\end{abstract}

Keywords: Childhood; Memorie; Space.

As pesquisas historiográficas sobre a infância e a criança cada vez mais estão se firmando e tem trazido várias inovações no uso das fontes, apesar das dificuldades encontradas.

A preocupação em desenvolver pesquisas com fontes que permitam o acesso às evidências diretas sobre as crianças continua presente (AREND; MOURA; SOSENKI, 2018). Com o objetivo de superar esse problema, pesquisadores e grupos investem na produção de fontes orais, no recolhimento de material produzido ou utilizado por crianças que seriam descartados (brinquedos, redações, desenhos, músicas, entre outros), principalmente nas instituições, tais como escolas e igrejas. Como afirma Stearns:

A história das crianças e da infância vem fascinando muitos historiadores contemporâneos, e o campo, neste exato momento, está uma vez mais ganhando terreno. Esses historiadores admitem que há aspectos da experiência das crianças que não podemos apreender totalmente, pela falta de evidência direta, porém sustentam que é

\footnotetext{
${ }^{1}$ Doutor em História Econômica, Professor Associado do Departamento de História na Universidade Estadual de Maringá. Brasil. E-mail: ajmorelli@uem.br | https://orcid.org/0000-0002-1917-3951
} 
possível reunir sólido conhecimento sobre a condição infantil no passado e sobre as mudanças na natureza da infância (STEARNS, 2006, p. 15).

No Brasil, esse processo ainda exige muitos investimentos e debates, muita pesquisa, assim como a estruturação de cursos de pós-graduação a respeito do tema. Exige, enfim, um grande movimento em prol da consolidação desse campo de estudo, o que inclui o levantamento e o inventário de fontes apropriadas para o aprofundamento das pesquisas. Como afirma Freitas:

Coordenar o Núcleo de Estudos Avançados em História Social da Infância tem exigido esforços contínuos no sentido de "mapear" a produção acadêmica a respeito do tema. Para além desse "mapeamento" um outro empenho sobreleva-se, qual seja o de organizar com rigorosos critérios arquivísticos fontes primárias para o estudo multidisciplinar da história da infância no Brasil. (FREITAS, 1997, p. 9)

As dificuldades apontadas para a realização de pesquisas com fontes diretas exigem o esforço do historiador em extrair dos mais diversos documentos as evidências relacionadas com a história das crianças. Esse esforço tem produzido bases mais sólidas para a criança ser estudada como objeto central, como agente histórico e não apenas como um grupo da sociedade que mereceu a atenção do Estado e de outras instituições por sua condição de tutelado.

Estudar a história da infância no processo de urbanização do Brasil também exige cuidados e criatividade. As fontes nos órgãos públicos, quando existem, raramente estão armazenadas com organicidade suficiente para possibilitar um acesso fácil e permitir analisar o processo de funcionamento desses serviços. No caso de cidades como Maringá, interior do Paraná, cujo crescimento é relativamente recente e distante dos grandes centros, a qualidade da preservação do acervo documental da Prefeitura é bastante precária, são muitas as dificuldades de acesso às informações e estas apresentam muitas lacunas no período analisado. A documentação referente ao município do final da década de 1990 em diante, apresenta maior organicidade e melhor preservação. Outra questão digna de nota é a importância que a criança conquistou nas últimas décadas, situação bem diferente antes do processo que levou à aprovação do Estatuto da Criança e do Adolescente em 1990.

O contato com a bibliografia e com as fontes, no processo de definição da pesquisa, apresentou o recurso da fonte oral como o mais indicado. Isto se dá primeiro pela possibilidade de um trabalho historiográfico mais próximo da infância; segundo, por possibilitar discutir o processo de urbanização mediante enfoque diferente das instituições e de seus discursos; terceiro, porque o trabalho com a memória permite analisar o passado recente, como é o caso, passado ainda com desdobramentos no presente. Deve-se entender sempre que o depoimento, fonte da pesquisa, é produzido no presente, é fruto do trabalho da memória com a influência da 
vida social do depoente até o momento da entrevista (MORELLI, 2010, 72-76).

É importante deixar claro que a pesquisa não se dirige à análise das instituições. $\mathrm{O}$ foco incide sobre a análise da memória de infância de moradores de Maringá durante a urbanização da cidade, entre 1970 e o decorrer da década de 1980. Na pesquisa que originou esse artigo, objetivou-se analisar o processo complexo de urbanização da cidade registrado na memória dos depoentes, principalmente daqueles que, na época, eram crianças, circunstância esta que ainda permitiu o aprofundamento na questão da formação da memória da infância nos adultos (MORELLI, 2010).

\section{A relação das crianças com o espaço}

A cidade de Maringá foi fundada no final da década de 1940, integrando a colonização do Norte do Paraná. Nas duas décadas seguintes, as características da cidade ficaram mais definidas. Maringá tornou-se centro de distribuição de bens e de prestação de serviços para a região, contando com investimentos empresariais e escritórios regionais de vários órgãos do governo estadual. Além disso, com o avanço do plantio de soja e outros produtos agrícolas, a produção de café deixou de ser a principal fonte econômica da cidade. Até o início da década de 1970, houve um crescimento demográfico expressivo, registrando-se cerca de $130 \mathrm{mil}$ habitantes (DIAS; GONÇALVES, 1999). Em 1967, foi elaborado, sob orientação do governo estadual, o Plano Diretor de Desenvolvimento que constatou a adiantada urbanização da região central de Maringá e a necessidade de ações públicas urgentes nas áreas periféricas. Para analisar como esse processo, desenvolvido entre 1970 e 1990, foi vivido pelas crianças da época, o uso de fontes orais demonstrou ser o mais indicado.

As entrevistas foram realizadas com pessoas que moraram em Maringá no período analisado, nascidas entre 1960 e 1980. Seguiu-se uma distribuição geográfica de suas moradias, estratégia que permitiu uma visão mais ampla da cidade, inclusive da periferia. A abrangência das perguntas possibilitou uma análise da relação dos entrevistados com o seu cotidiano: moradia, alimentação, brincadeiras, trabalho, relações de vizinhança e dos adultos com as crianças; e com a cidade e os serviços oferecidos: saúde, educação, lazer, transporte, entre outros $^{1}$. O trabalho com as fontes orais, além de analisar como o processo complexo de urbanização da cidade ficou registrado na memória dos depoentes, ainda permitiu o aprofundamento na questão da formação da memória da infância nos adultos (MORELLI, 2010, p. 69). 
$\mathrm{Na}$ casa, no bairro ou na escola, as brincadeiras recebem destaque nas falas, aliás momento que permite algumas considerações sobre a identificação dos brinquedos com o consumo. A riqueza de detalhes em relação aos brinquedos e brincadeiras presente nessa fase contrasta com algumas afirmações: "não tinha brinquedos, não" ou "meu pai não podia comprar brinquedos". Os brinquedos feitos artesanalmente, relatados de forma minuciosa em alguns casos, confundem-se com o sentido próprio do momento em que ocorre a entrevista, ou seja, em que os brinquedos são, em larga medida, adquiridos no comércio. As festas representam uma passagem, o final da infância, quando os depoentes "deixam de ser crianças" e passam, aos poucos, a interagir de maneira diferente com a comunidade. As festas, apresentadas como principal forma de diversão e de encontros com os demais, aconteciam nas escolas, nas casas dos amigos, nas igrejas. Estas últimas, uma tradição da cidade, como afirma um entrevistado: "todo mês tinha festa de um santo". Além disso, mantendo presentes as questões apontadas no Plano Diretor de Desenvolvimento, procurou-se perceber como a população infantil se relacionava com os serviços públicos, principalmente os relativos à saúde e à educação.

A relação das crianças com o espaço, sua ocupação e uso com brincadeiras foi um ponto recorrente nas entrevistas. A relação com o espaço é uma variável importante para entender como a criança ocupava seu tempo livre, quais eram suas brincadeiras, seus pequenos trabalhos, relacionamentos e como interagia com a cidade.

As ideias de espaço, relacionadas com a experiência vivida, partem do mais próximo para o mais distante, pois seu funcionamento é semelhante à própria experiência do conhecimento, como afirma Tuan:

A ideia de lugar da criança torna-se mais específica e geográfica à medida que ela cresce. À pergunta "onde gosta de brincar?", uma criança de dois anos provavelmente dirá "casa" ou "fora". Uma criança mais velha responderá "no meu quarto" ou "no quintal" (TUAN, 1983, p. 34).

Detalhe aparentemente sem importância para os adultos que observam é, para a criança, a construção do mundo fazendo uso de coisas que passam a ser "humanizadas". Como no romance "O meu pé de laranja lima” (VASCONCELOS, 1980), no qual uma árvore é eleita pelo menino Zezé como sua amiga. Assim, a criança elege os espaços em relações imbricadas com objetos, estruturas naturais ou artificiais: o galho que ganha contornos especiais por ser "parceiro" para brincadeiras como de balanço na árvore; o pé de abacateiro que fornece material e sombra para a fazendinha; ou a laranjeira que se torna preferida para brincar de casinha. Nas palavras de Tuan "À medida que a criança cresce, vai-se apegando a objetos, em lugar de se 
apegar a pessoas importantes, e finalmente a localidades. Para a criança, o lugar é um tipo de objeto grande e um tanto imóvel” (TUAN, 1983, p. 33).

A identificação com determinados espaços é bastante explícita nas falas ${ }^{2}$ referentes às lembranças das brincadeiras: "Nádia33: no sítio que nós morávamos, ele era muito bem distribuído assim, tinha aquele terreirão imenso e a gente trabalhava lá, trabalhava não, brincava lá de queima, de betis ${ }^{4}$, porque tinha muito espaço e tinha muita árvore pra gente brinca, subi...".

Assim, mesmo existindo muitas áreas livres, a identificação com algum local parece ter um valor maior, um ponto de encontro:

Mara5: [...] vamu brinca de casinha, vamu, debaixo de um pé de laranja, fazia lá ... gente brincava, ia numa casa ou na outra aí juntava os amigos, amiguinho e a gente ia faze balanço, e numa árvore enorme se chamava painera a gente fazia um balanço bem alto e ainda coloca corda comum bambu pode coloca de tanto alto que era né... tão dava um balanço delicioso.

A importância dada pelas crianças aos espaços que lembram algum prazer ganha em sua imaginação contornos quase mágicos, principalmente quando relatam esses momentos. Como define Bosi:

O espaço da primeira infância pode não transpor os limites da casa materna, do quintal, de um pedaço de rua, de bairro. Seu espaço nos parece enorme, cheio de possibilidade de aventura. A janela que dá para um estreito canteiro abre-se para um jardim de sonho, o vão embaixo da escada é uma caverna para os dias de chuva. (BOSI, 1987, p. 356)

Espaços simples ganham cores, a grama torna-se "verdinha", e os tamanhos de salas, móveis, árvores perdem as reais dimensões, ficam enormes, como uma depoente mesmo analisa:

Nádia: Então as salas... elas eram enormes, enorme mesmo, é... tanto que eu lembro que tinha... colocava um sofá aqui, dois sofazinhos, uma mesa num canto i... ficava aquele espaço imenso assim. Agora tem um detalhe eu num sei se o espaço era tão grande assim, ou se a minha memória que fez, porque eu era criança quando eu morava lá né, mas o que eu me lembro é que era tudo muito amplo...

Os espaços talvez não fossem enormes apenas na memória da infância como se percebe nos relatos analisados:

"tinha aquele terreirão imenso"

"as salas... elas eram enormes"

"a escola era grande, eu achava que era um monte de alunos não sei se era realmente, mas achava gigantesca" 
Os comentários sobre os espaços demonstram a relação íntima com as atividades desenvolvidas, sendo que a importância dada a determinado local varia de acordo com o tema abordado pelo depoente. Os espaços especiais de infância, como relatado anteriormente, ganham magia, sugerindo momentos íntimos, algo especial. Representam, pois, tanto um espaço especial individual, quanto um lugar eleito para os encontros, para dividir momentos com os amigos, irmãos, enfim, parceiros de brincadeiras ao vivenciar a infância.

Analisando o pensamento de Halbwachs referente à lembrança de sua participação em um grupo, Márcia Mansor D’Aléssio afirma:

Se, no presente, alguém não se recorda de uma vivência coletiva do passado é porque não pertencia àquele grupo - ainda que pertencesse fisicamente --. Já que é o afetivo que indica o pertencimento. A partir daí, é possível supor que é tecida uma espécie de cadeia de pertencimento afetivo que mantém a vida e/ou o vivido da memória (D’ALÉSSIO, set.92/ago.93, p. 98-99).

A parte relevante para a discussão aqui em curso é a relação de pertencimento, a relação afetiva que mantém ou exclui a memória. No caso, trata-se da relação afetiva da criança com o espaço, tão ou mais importante que uma relação pessoal ocorrida na infância. Trata-se de uma relação com o espaço que vai além do que está claramente expresso, abarcada em suas potencialidades de lazer, diversão, brincadeiras.

A passagem a seguir mostra que a distância do centro da cidade, o quase isolamento pelo reduzido número de moradores são elementos que não se traduzem unicamente em dificuldades. Há neles uma dimensão lúdica: "Joana': [...] era quase que desabitado, porque tinha assim uma ou duas casas em cada quarteirão, não tinha água, não tinha luz e não tinha asfalto, era uma beleza (risos), em compensação tinha muita rua para se correr, muito terreno baldio para se brincar tudo[...]".

Joana refere-se à sensação de liberdade que experimentava nesse novo espaço. Encontra nos terrenos baldios e nas árvores próximas uma compensação da saída do sítio em que vivia antes de sua família mudar-se para Maringá. O aproveitamento do espaço é constante nos relatos sobre brincadeiras, principalmente no caso da infância que possui poucos recursos materiais. Então, a interação com a natureza passa a ser condição necessária para suprir as necessidades lúdicas da infância. A análise dos brinquedos deixará clara essa questão de produção de brinquedos e objetos para brincadeiras. E nem sempre o espaço precisa ser mudado ou adaptado fisicamente. Por exemplo, o galho virava um avião de onde se saltava de paraquedas, existente só na imaginação do autor da façanha. 
A passagem a seguir reforça a capacidade de aproveitar os momentos e os espaços disponíveis. Mais do que isso, mostra a relação com os adultos e com as atividades diárias:

Mara: [...] à noite a gente gostava de brincar, à noite, toda noite... em frente de casa tinha um pasto, a grama assim verdinha bem limpinha. A gente colocava um saco de estopa e ficava um puxando o outro na grama, na descida assim sabe, enquanto os pais ficavam conversando dum lado as crianças ficavam bem longe pra num atrapalha a conversa né... ficava brincando até certa hora, depois ia todo mundo dormi, pra levanta cedo no outro dia.

O pasto para o tratamento dos animais vira pista para as crianças escorregarem e o "em frente de casa" não parece ser tão próximo, afinal "ficavam bem longe dos adultos para não atrapalhar a conversa", deixando-os livres para conversar e mantendo-se livres para as brincadeiras. O uso de áreas para animais aparece em vários depoimentos e em diferentes momentos:

Joana: só tinha colonião então a gente tinha que busca as vacas no final do dia lá. Então isso era uma brincadeira né, era uma brincadeira e um serviço. Era brincadeira porque o colonião era mais alto que a gente, então a gente ficava hunnnn... encontra uma cobra que a gente tinha medo, que tinha lá...

Uma situação cotidiana, buscar as vacas para prender, mostra-se uma aventura constante. As crianças precisavam passar pelo capim mais alto do que elas, com a possibilidade de encontrar cobras, e voltar tocando as vacas. O medo de cobra, a responsabilidade da tarefa, o esforço necessário novamente misturam-se com a brincadeira entre os irmãos no escondeesconde quase forçado. A capacidade de transformar os espaços, criando condições lúdicas, é própria da criança, chegando, em alguns casos, à criação de um espaço especial, só dela, pois ninguém mais vê aquilo que sua imaginação criou:

O lugar pode adquirir profundo significado para o adulto através do contínuo acréscimo de sentimento ao longo dos anos. Cada peça dos móveis herdados, ou mesmo uma mancha na parede, conta uma estória. A criança não apenas tem um passado curto, mas seus olhos, mais que os dos adultos, estão no presente e no futuro imediato. Sua vitalidade para fazer coisas e explorar o espaço não condiz com a pausa reflexiva e com a olhada para trás que fazem com que os lugares pareçam saturados de significância. A imaginação da criança é de um tipo especial. Está presa à atividade. Uma criança cavalga um pau como se estivesse sobre um cavalo de verdade, e defende uma cadeira virada como se fosse um verdadeiro castelo. (TUAN, 1983, p. 37)

São vários os exemplos do uso dado a determinados espaços, diferente do destinado originalmente, principalmente os da área de trabalho. Importa, agora, deixar claro que os espaços eram usados de maneira diversa, inclusive para brincadeiras, mesmo onde ocorria o 
trabalho. Esse uso apareceu espontaneamente nas entrevistas. Porém, nas situações relacionadas ao trabalho mais severo, não são mencionadas as brincadeiras e "não podia brincar" era a reposta. Nos momentos em que o enfoque principal recaía sobre o trabalho, a ênfase no espaço se desfazia quase completamente. Isto é perceptível nos casos em que o trabalho representava esforço cotidiano, imposto e evidentemente contrário aos anseios do depoente. Então, as descrições ganham tonalidade fria: "eu trabalhava na roça...", "íamos carpi”, "trabalhava de olhar o filho da vizinha", "não tinha tempo de nada, trabalhava de doméstica de segunda a sábado". Algumas vezes, o mesmo local se transforma nos depoimentos, como o pasto na hora de brincar e na hora de trabalhar.

O uso dos espaços não pode ser visto como uma prática não conflituosa. $\mathrm{O}$ aumento das construções, do trânsito dos veículos e das pessoas provocaram a diminuição dos espaços, e os que restavam para o lazer eram redefinidos. Esta situação evidencia-se tanto em relação às crianças que viviam mais próximas do centro urbano, como às que viviam na periferia. Esse processo ocorreu em dois movimentos básicos: o desenvolvimento da área central - com residências, comércio etc. - e a maior concentração de habitantes - diminuindo os grandes terrenos vazios, configurando-se a imagem dos quarteirões, aproximando-se uns dos outros e mesmo envolvendo os sítios existentes no perímetro urbano.

Uma forma para superar essas condições era a ocupação progressiva e o uso, pode-se dizer sistemático, para manter a "posse" por quanto tempo fosse possível. O relato de Reginaldo Dias evidencia esse processo de identificação e conflito com as mudanças:

Era a crônica de uma espécie de morte anunciada, notícia triste para os meninos que residiam, no início da década de 1970, na Rua Itapura, Vila operária. O nosso campinho de futebol localizado nos fundos do Posto de Puericultura, estava com sua extinção determinada. Tratava-se de um terreno da prefeitura, destinado à construção de algum equipamento público. [...] torcíamos para que a nossa posse informal se estendesse o máximo de tempo [...] Bem vistas as coisas, talvez o nosso sentimento, ingênuo na essência, nem chegasse a ser mesquinho, pois o lazer também é interesse público (MARINGÁ, 2002, p. 12).

A passagem anterior é instigante e revela o conflito de interesses de crianças da Vila Operária com as decisões governamentais. A memória de Reginaldo Dias apresenta um exemplo da relação da infância com os interesses dos adultos. Trata-se da destinação de um terreno baldio para a instalação de serviço público, a fim de atender à população da região, desconsiderando a importância do lugar para as crianças. Qualquer adulto poderia pensar que elas achariam outro terreno sem nenhum problema, mas aquele era o espaço delas. 
$\mathrm{Na}$ área central ou nas regiões mais populosas, a definição e a ocupação dos espaços exigiam outras estratégias. Por exemplo, quando as posses permitiam esse acesso:

Clara $^{7}:[\ldots]$ mas antes era um campo de futebol, então a gente tinha espaço enorme de quintal, vamus dize que não era um quintal de uma casa, mas era o quintal ligado ao prédinho que eu falo apartamento, mas era o apartamento que embaixo tinha uma loja e em cima tinha dois apartamento, então não era uma estrutura de prédio, era um pouco diferente porque a gente vê que a criançada que mora em prédio, já tem espaço pra brinca, porque tem o limite das normas, e ali era apartamento, mas era uma mistura de apartamento com espaço de casa porque tinha esse terreno ao lado... meu pai fez um campinho de futebol pros meus irmãos. Mas também a gente brincava no fundo tinha um espaço legal sabe. Então era, acabava sendo um ponto de referência porque tinha espaço em casa.

Os espaços livres diminuem pela ocupação definitiva ou pela previsão de seu uso para residências, prédios comerciais ou públicos e mesmo praças. A urbanização, em seu processo de definição dos espaços, lentamente delineia o local onde tudo deve acontecer, mesmo que não funcione totalmente como previsto.

Questionados sobre as mudanças que ocorriam na cidade, tais como o crescimento demográfico, o maior movimento nas ruas, a ampliação de serviços públicos e privados, a ocupação dos espaços com casas e prédios, as mudanças do espaço e da própria cidade, percebese que nada disso possuiu grande representatividade ou permaneceu claro na memória dos entrevistados. Ocorre, contudo, uma alteração no tom da entrevista: a referência a mudanças causa momentos de parada e de reflexão mais perceptíveis que em outras situações. Uma atitude marcante quanto à relação do depoente com o espaço vivenciado como criança e o espaço vivenciado em outras fases da vida.

Essa mudança do tom da entrevista aconteceu quando o depoente descrevia os espaços coletivos, sem a conotação do brincar, ou quando tratava das características da cidade. Falar de como os alimentos eram conseguidos, da descrição da casa, do sítio, do asfalto ou da falta dele, dos processos para conseguir água ou iluminar a casa consistia em abordar assuntos sérios, afinal nem tudo era brincadeira. Tornavam-se, assim, menos emotivos e mais descritivos, mesmo tratando de situações relacionadas com melhorias na qualidade de vida e maior acesso aos recursos urbanos, como a maior facilidade de compra ou maior oferta de produtos, ou quando passaram a contar com os serviços de energia elétrica e de água encanada. Seu pouco interesse em tratar dessas mudanças deitou por terra a expectativa de que pudessem ter um peso considerável nos relatos. Por outro lado, reforçou a disposição dos depoentes de falarem das atividades de quando eram crianças, de seu envolvimento com a própria infância. 
A memória sobre as mudanças está presente nos depoimentos, porém de maneira diluída na fala relativa a outros assuntos, casos da menção ao acesso a ruas asfaltadas, quando o depoente relata uma mudança de residência, e da dificuldade demonstrada em tratar do asfaltamento das ruas do bairro em que morava. A percepção, com exceção de mudanças bruscas, não identifica como mudança o que é observado no dia-a-dia. Como diz Clara: "eu não sentia o cotidiano da cidade". As mudanças que ocorriam no dia-a-dia, como o aumento contínuo da população, por exemplo, acabavam não sendo percebidas. As mudanças na cidade como o aumento de casas e de prédios, as novas áreas desmatadas e ocupadas, o volume de veículos parecem mais perceptíveis para os que se ausentam e depois retornam. A condição de afastamento demonstrou ser uma condição efetiva na formação da memória de uma cidade urbanizada e com diferenças significativas em relação ao período de criança dos depoentes:

Nádia: não, não sei se era perceptível, eu não percebi, eu só fui perceber esse aumento, esse crescimento quando eu saí de Maringá que foi em 93, perdão no comecinho de 93, aí toda vez que eu voltava...

Clara: mas eu não sentia o cotidiano da cidade e quando eu voltei pra mora em Maringá, que eu tive assim um impacto quanto que Maringá tinha crescido e como a gente já não conhecia mais todo mundo, como mudo né.

Essa situação é marcante se comparada com as entrevistas feitas com os pioneiros e hoje armazenadas no acervo da Prefeitura Municipal de Maringá ${ }^{8}$. A mudança é elemento constante nos depoimentos dos pioneiros, tanto de homens como de mulheres. Da mata que seria derrubada até a cidade que Maringá se tornaria, há um processo constante, marcado por dificuldades a serem superadas. Nas entrevistas com a nova geração, Maringá não possui mais essa característica, é a cidade em que vivem, e o tempo parece mais lento do que para os pioneiros. O impacto das mudanças parece menor. O discurso e o objetivo dos pioneiros estavam forjados na ideia de crescimento, de formar uma nova e grande cidade.

Nos depoimentos analisados, as mudanças constantes, que nem sempre possuíam impacto, chamavam pouco a atenção, de tal forma que não figuravam claramente nas lembranças da infância dos depoentes. Além de um fenômeno analisado por Halbwachs (1990, p 137-138): a resistência em assimilar as mudanças, procurando se ater aos elementos que não mudaram ou ao que é conhecido. O conhecido pode possibilitar maior conforto na relação com o mundo. Quando se afastaram do grupo, saindo da cidade, no retorno as mudanças chamaram a atenção. 
A relação da pessoa com o espaço, como afirma Tuan, tende a seguir o processo do mais intimista para o grupo social mais amplo:

No homem adulto são extremamente complexos os sentimentos e ideias relacionados com espaço e lugar. Originam-se das experiências singulares e comuns. No entanto cada pessoa começa como uma criança. Com o tempo, do confuso e pequeno mundo infantil, surge a visão do mundo do adulto, subliminarmente também confusa, mas sustentada pelas estruturas das experiências e do conhecimento conceitual. (TUAN, 1983, p. 22)

A relação com o espaço é demarcada com o entorno da casa ou adjacências do bairro e fala-se muito das dificuldades de locomoção. As referências a outros lugares da cidade ocorrem nos momentos específicos de fazer compras, buscar algum serviço, ir para a escola. O transitar pela cidade, de um bairro a outro, ou ir para o centro muda quando o depoimento diz respeito à adolescência. O mundo amplia-se, o trânsito fica mais livre; por outro lado, o ir e o vir ficam mais delimitados aos objetivos, ou seja, quando saem com os amigos, um passeio ao cinema, ao parque, às festas. Esse fenômeno do alargamento dos limites foi percebido nas entrevistas.

As características da casa, do quintal e da vizinhança tornaram-se mais precisas à medida que foram relacionadas com os momentos da infância. Quanto mais próximos estão os depoentes da adolescência, os comentários ficam mais concisos, com descrições mais sucintas ao falarem do baile, dos acontecimentos da cidade, dos relacionamentos pessoais. O espaço perde importância, os objetos perdem a cor; a grama não é mais tão verdinha, como no relato de infância. As brincadeiras, os brinquedos, o uso que as crianças fazem do espaço que é por elas apropriado para seu mundo de fantasia, a fase de interação, tudo isso permitiu que os depoentes elaborassem uma definição de como foi sua infância na cidade de Maringá.

\section{Considerações finais}

Com todas as pesquisas das últimas décadas tem ficado claro que não se deve falar em infância, mas em infâncias, ainda que em um mesmo período, em uma mesma localidade. A relação adulto/criança, apesar de possuir traços que podem ser agrupados, ainda assim apresenta especificidades. As características de um grupo podem ser vistas de forma diferente por outros grupos. E, quando se faz a análise de uma comunidade, de um bairro, de uma cidade, inevitavelmente haverá o contato com essa pluralidade e, portanto, com essas diferenças. Como afirma Stearns:

Todas as sociedades ao longo da história, e a maior parte das famílias, lidaram amplamente com a infância e a criança. Muitas características são padronizadas, independente de tempo e lugar. Sempre e em toda parte, as crianças precisam receber 
alguma preparação para o estágio adulto. Necessitam aprender a lidar com determinadas emoções, como raiva ou medo, de forma socialmente aceitável. Sempre e em toda parte, em vista do longo período de fragilidade na infância da espécie humana, crianças pequenas requerem que se lhes providenciem alimentação e cuidados físicos (STEARNS, 2006, p. 12).

A relação do adulto com a criança, diretamente com filhos ou em ações mais abrangentes, recebe cada vez mais atenção, seja pelos estudos de diferentes áreas, seja pelos órgãos de defesa dos direitos da infância. Esse processo é percebido nos depoimentos quando os depoentes falam de seus filhos, quando avaliam as condições atuais de maneira mais ampla ou nas passagens em que rememoram as dificuldades que enfrentaram para conseguir algo que consideram mais fácil de ser obtido atualmente. A expressão de Rita de que "hoje só não estuda quem não quer" é um claro exemplo.

A relação adulto/criança está marcada muito mais pelas condições de comportamento do que pelas faixas etárias. A situação é perceptível quando se buscam as definições etárias. A definição de uma idade limite pode estar baseada na capacidade que tem ou não a pessoa de responder pelos seus atos ou nas características físicas e hormonais, porém o estabelecimento de atitudes consideradas infantis é mais fácil de ser aceito, tanto pela sociedade em geral quanto pela comunidade científica.

A caracterização da criança envolve inúmeras questões discutidas por diversas áreas do conhecimento. Preocupação essencial quando o pesquisador define seu objeto, porém, muito mais do que isso, trata-se de uma fase vivida por todos um dia. Ser adulto está configurado em um discurso e em cobranças diretas, significando não ser mais criança e ter superado também a fase da adolescência, possuindo como princípios mais comuns a disciplina e o distanciamento das brincadeiras.

Essa maneira de agir dos entrevistados ressaltou uma questão: a intensa relação do depoente com o período de que fala, ou seja, os relatos são de pessoas adultas, que conhecem a cidade, inclusive nos anos seguintes ao período tratado. Porém a fala demonstrava uma relação direta com o momento relatado. A própria fala, não desconsiderando a condição de liberdade que se tentou proporcionar aos depoentes durante a entrevista, possui características do período. A esse respeito, Bosi aborda o assunto de maneira esclarecedora:

O caráter livre e espontâneo, quase onírico da memória é, segundo Halbwachs, excepcional. Na maior parte das vezes, lembrar não é reviver, mas refazer, reconstruir, repensar, com imagens e idéias de hoje, as experiências do passado. A memória não é sonho, é trabalho. [...] A lembrança é uma imagem construída pelos materiais que estão, agora, à nossa disposição, no conjunto de representações que povoa nossa consciência atual (BOSI, 1987, p.17). 
Conforme verificamos nessa pesquisa, o processo de análise da memória de infância, duas preocupações são básicas: o que no período de criança teve importância suficiente para ser registrado e quais os elementos do presente que participam desse trabalho de reconstrução do passado. E a produção historiográfica sobre infâncias e crianças, inclusive no que tange à memória, assim como as pesquisas diretas com crianças, têm apresentado repercussões em outras áreas, criando um novo movimento. Nas escolas, por exemplo, as pesquisas sobre as brincadeiras têm proporcionado uma interação dos professores e dos pais com as crianças, em exercícios de comparação e difusão delas. Essas atividades, além dos momentos lúdicos que proporcionam, contribuem para reflexões mais profundas e abrangentes sobre a utilização do espaço pelos alunos e a importância das brincadeiras na formação intelectual e social das crianças. O cuidado dos adultos com a forma como as crianças lidam com o espaço possui, assim, uma grande importância nas infâncias e na formação de nossas memórias.

\section{Referências bibliográficas}

AREND, S. M. F.; MOURA, E. B. B. de; SOSENKI, S. Infâncias e juventudes no século XX: histórias latino-americanas. Ponta Grossa: Todapalavra, 2018.

BOSI, Ecléa. Memória e sociedade: lembranças de velhos. 2 $2^{\text {a }}$ ed. São Paulo: T. A. Queiroz/EDUSP, 1987.

D’ALESSIO, Márcia Mansor. Memória: leituras de M. Halbwachs e P. Nora. Revista Brasileira de História, São Paulo, v. 13, n. 25/26, p. 97-103, set.92/ago.93.

DIAS, R. B.; GONÇALVES, J. H. R.. Maringá e o norte do Paraná: estudos de história regional. Maringá: EDUEM, 1999.

FREITAS, Marcos Cezar (org.). História Social da Infância No Brasil. São Paulo: Cortez, 1997.

HALBWACHS, Maurice. A memória coletiva. São Paulo: Vértice, 1990.

MARINGÁ. Memória de bairros: Vila Operária. Prefeitura Municipal de Maringá: s/n., 2002.

MORELLI, A. J. Memórias de infância em Maringá: transformações urbanas e permanências rurais (1970/1990). São Paulo, 2010. Tese (Doutorado) - Faculdade de Filosofia, Letras e Ciências Humanas, Universidade de São Paulo, São Paulo, 2010.

STEARNS, Peter Nathaniel. A infância. São Paulo: Contexto, 2006.

TUAN, YI-FU. Espaço e lugar: a perspectiva da experiência. São Paulo: DIFEL, 1983.

VASCONCELOS, José Mauro de. O meu pé de laranja lima. São Paulo: Melhoramentos, 1980. 


\begin{abstract}
${ }^{1}$ Os tópicos eram sugeridos quando não haviam sido abordados ou quando se percebia um momento propício para tratar deles, sempre, porém, com o mínimo de intervenção. As entrevistas foram realizadas em um único encontro, dado o interesse de analisar o depoimento em seu estado mais direto, sem interferência de outras reflexões ou revisões, objetivando a construção de uma fonte mais próxima desse primeiro contato com as questões apresentadas, uma memória da infância que permitisse uma aproximação da relação da criança com a urbanização da cidade. Dentre os depoentes, alguns moravam em sítios na zona urbana, situação que persistiu até os dias atuais, apesar de que com menor frequência. As casas eram de madeira, em sua maioria, em áreas mais afastadas ou próximas do centro. Foram mencionados seus quintais, a vizinhança e as melhorias básicas que chegavam aos poucos: as mudanças da lama das ruas para o asfalto, da água do poço para a encanada e da luz da lamparina para a elétrica. Os depoimentos não serão apresentados integralmente neste trabalho. No desenvolvimento da análise, foram selecionados os trechos considerados mais significativos, evitando-se o excesso de repetição de falas muito próximas. Alguns trechos, por outro lado, são utilizados mais de uma vez, considerando a riqueza de questões que concentram. A transcrição aparece citada com alguns ajustes, com os vícios de linguagem reduzidos, garantindo o teor da fala sem prejudicar seu entendimento. Outra medida assumida no uso dos depoimentos foi a substituição dos nomes dos depoentes, apesar da autorização expressa do uso integral dos depoimentos e sua identificação.

${ }^{2}$ A transcrição aparece citada com alguns ajustes, com os vícios de linguagem reduzidos, garantindo o teor da fala sem prejudicar seu entendimento. Outra medida assumida no uso dos depoimentos foi a substituição dos nomes dos depoentes, apesar da autorização expressa do uso integral dos depoimentos e sua identificação. Porém, sendo um trabalho elaborado a partir de fragmentos das falas e inferência nas mesmas, a identificação do depoente não
\end{abstract} parece justa, além dessa mudança não interferir na integridade do texto.

${ }^{3}$ Nádia, nasceu em Maringá no final da década de 1960. Sua infância corresponde aos primeiros anos de 1970 e à década de 1980. Morava, inicialmente, na região mais afastada da Zona Cinco em um sítio no limite com a zona rural. Posteriormente, a família mudou-se para uma chácara, também na Zona 5, porém mais próxima da área urbanizada.

${ }^{4}$ Betes, bets ou taco é um jogo que consiste em duas duplas, uma com os bastões (tacos ou betes), protege uma casinha (um pino dentro da área onde fica o rebatedor). A outra dupla, os lançadores, fica atrás dos rebatedores em lados opostos no campo. O lançador lança a bola com o objetivo de derrubar a casinha, ganhando o direito de a dupla passar para rebatedores. Caso a bola bata no rebatedor é vantagem para os lançadores; se bater no taco e for para trás também é uma vantagem; três vantagens, ou três faltas dos rebatedores, duplas mudam de função. Quando o rebatedor acerta a bola eles podem cruzar o campo e bater os tacos no meio, contando ponto cada vez que cruzam o campo. Porém, se enquanto estiver fora da cela o lançador conseguir pegar a bolinha e acertar um rebatedor, este perde o último ponto e passa para lançador. Os pontos necessários para término do jogo variam de acordo com as regiões.

${ }^{5}$ Mara veio com a família para Maringá, onde o pai foi contratado para "tocar um sítio de café". Chega no final da década de 1960, com nove anos aproximadamente (não tem clara a idade e o ano da chegada). A localização do sítio é bastante afastada da área central, porém, mesmo com todas as características rurais, faz parte da ampliação da área urbana.

${ }^{6}$ Joana, nascida em cidade próxima de Maringá onde os pais eram proprietários de sítio, mudou-se ainda nos primeiros anos de vida, no início de 1970, provavelmente entre cinco e seis anos. Da cidade natal lembra-se de acompanhar a família nos trabalhos na roça e as irmãs na escola rural.

${ }^{7}$ Clara nasceu em cidade da região de Maringá no final de 1960, de família com posse de terras e moradores na área urbana. O pai, formado em odontologia, exercia a profissão antes de mudar com a família para Maringá. Como na cidade de origem, foram morar na área central, no centro da cidade, desde seus primeiros anos de criança. ${ }^{8}$ Acervo oral do Projeto Memória está armazenado na Gerencia de Patrimônio Histórico e Cultural da Secretaria Municipal de Cultura, antiga Divisão de Patrimônio Histórico e Cultural (DPHC) da Prefeitura Municipal de Maringá. $\mathrm{O}$ acervo é produto de um projeto voltado à preservação da memória de Maringá e está dividido em dois conjuntos. O primeiro constitui as entrevistas realizadas entre 1985 e 1987, efetuadas por voluntários e registradas em aproximadamente 130 fitas de áudio. O segundo, iniciado em 1992, transformou-se em uma atividade permanente da Gerência de Patrimônio, sendo realizado ou acompanhado por funcionários da secretaria de cultura. 